\title{
Asylum Seekers and the Refugee Determination Procedure
}

\author{
Extracts from a Position Paper by the Refugee Council of Australia
}

\section{On categorization of asylum seekers:}

a) The statutory fiction that deems people not to have entered Australia should be removed.

b) All claimants for refugee status should be afforded the same treatment and entitlementsirrespective of whether they applied at the border or after entering the country.

\section{On visa requirements and carrier sanctions:}

a) The Australian government should take urgent action to ensure and to demonstrate that the current visa requirements for foreign nationals wanting to visit Australia and the practice of fining airlines and other carriers who allow passengers without visas to arrive in Australia does not obstruct bona fide asylum seekers from gaining effective access to Australia's refugee determination procedure.

b) If the above cannot be adequately demonstrated, steps should be taken as a matter of priority to amend legislation to ensure that such obstacles are removed.

\section{On the entitlements of asylum seekers:}

All claimants should be entitled to: a) Freedom to live in the communityexcept in special circumstances and the right to engage in paid employment.

b) Access to consideration for humanitarian status.

c) Access to legal assistance.

d) Access to benefits.

\section{On detention:}

a) The government's practice of detaining asylum seekers should be abolished. b) Detention should only be used under special defined circumstances, such as to establish the identity of the claimant or if the claimant is found by a magistrate to be a risk to the community (e.g., if they have a serious criminal record).

c) Persons under 18 years of age should not be detained under any circumstances.

d) There should be regular judicial review of a decision to detain an asylum seeker to assess whether continued detention isjustified according to various predetermined criteria.

e) Conditions of detention should be subject to defined standards as outlined below.

f) No detainees should be held in penal institutions.

Where detention is used, RCOA contends that the following standards should be observed:

a) there should be regular judicial review of the need to detain.

b) There should be opportunities for regular day release for the purposes of recreation, training, religious observance, employment, etc.

c) There should be provision for community release subject to specified conditions, e.g., bond on regular reporting.

d) The conditions of detention should be subject to defined standards and be in accordance with Australian and international laws. In particular, there should be access to:

i. accredited interpreters

ii. education:

- full curriculum for school-aged children (if detained), including instruction in their native language and culture

- vocational training for adults

- English language training

iii. recreational pursuits

iv. the services of a welfare worker

v. culturally appropriate medical and dental care vi. specialized torture and trauma counselling, with accredited interpreters available

vii. legal advisers

viii. appropriate religious support (both for spiritual reasons and to enable the observance of festivals, rights of passage, etc.)

ix. visitation from relatives and friends $x$. permission to keep belongings (except where it is deemed that there is a security risk)

xi. the right to open their own mail (in the presence of an official of the Department of Immigration if deemed necessary)

e) In order to ensure the provision of the above services, detention centres should only be located in major population centres, such as Sydney and Melbourne. f) All staff who come into contact with the detainees should be trained in crosscultural communication and carefully briefed as to how to work with them.

\section{On access to humanitarian protection:}

a) There should be separate categories of refugee status and humanitarian status with provision to apply for either.

b) Consideration for humanitarian status should be based on broader predetermined criteria, including the protection of people for whom there is a demonstrable risk if they were to return to their country of origin for reasons other than those outlined in the Convention (such as natural disaster, civil war, etc.).

c) Power should be vested in Department of Immigration case officers to recommend a refugee status applicant for humanitarian status at various predetermined points in the assessment process, including at the point of entry, without jeopardizing their refugee consideration if humanitarian protection is refused. 
d) Access to humanitarian status should not be determined by mode of arrival in Australia or status on application.

\section{On legal advice for asylum applicants:}

a) The Department of Immigration should fund independent legal/ paralegal advice services for refugee status applicants to ensure that those who do not have the means (financial, language, community support) to access other services have access to this service. b) The Migration Act should be changed to place the onus on the Department of Immigration in the current situation to provide the following for detainees prior to and during the determination process:

i. independent legal advice

ii. independent accredited interpreters to work with the legal advisers.

c) No assessment on the merits of the claim of a border applicant or illegal entrant should be made until their independent legal adviser has had an opportunity to adequately explain their role and the refugee determination process.

d) Legal advisers should be able to refer clients to psychiatrists for assessments if these are considered necessary to substantiate the claim.

\section{On the provision of benefits for asylum seekers:}

a) Once a claim of substance has been established, all asylum seekers not in employment should be entitled to income support provided by the government and administered by a government department with the appropriate infrastructure.

b) Asylum seekers, once registered as having submitted a claim, should be eligible for medical benefits.

It is RCOA's position that a just, fair and effective procedure for assessing the primary claims of refugee status applicants:

- should not discriminate against asylum seekers on the basis of their beliefs, colour, sex, ethnic origin, language or religion
- should not discriminate on the basis of immigration status at the time of applying; and

- in addition, include the following:

a) Department of Immigration case officers and other staff dealing with asylum claims should be carefully selected for their background knowledge and aptitude to this work.

b) All case officers and other staff in this area should receive comprehensive training. Training should address issues such as racism, compassion fatigue and cross-cultural communication.

c) The decisions of case officers and delegates should be subject to regular review.

d) Decision-making staff should be required to keep up to date with developments in countries from which claimants come and that in doing so, they access information from a wide range of nongovernment as well as government sources.

e) The procedures employed should be administratively effective.

f) The primary application stage should include:

- a written application form

- an oral hearing, with provision for the presentation of evidence and the calling of witnesses, especially in relation to psychiatric and medical evidence

- sufficient time to collect documentary evidence and/or to recover from trauma

- full public access to all information used in the determination process

- access to UNHCR advice

g) Determination should be in accordance with the UNHCR Handbook for Procedures for Determining Refugee Status under the 1951 Convention and 1967 Protocol.

h) Applicants should be afforded the benefit of the doubt.

i) There should be three possible outcomes of the application: acceptance for refugee status, recommendation for humanitarian status or rejection of the claim.

j) All successful refugee status applicants should be eligible for permanent residence (not the Temporary Entry Permits they are given at present and which result in prolonging the refugees' feeling of being in limbo).

k) The time frames for lodging applications and responding to decisions should be adequate and flexible (if grounds can be shown for requiring extensions).

1) There should be a process of regular independent review of the procedure to ensure adherence to the 1951 Convention (and other instruments and laws as deemed appropriate).

\section{On the appeal mechanism for refugee status determination:}

As a result of perceived problems with the operation of the Refugee Status Review Committee, RCOA supports:

- disbanding of the existing RSRC

- the establishment of a totally independent review mechanism with decision-making powers to examine appeals by rejecting refugee status applicants

- the participation of community representatives nominated by the Refugee Council in the review mechanism together with other independent people chosen for their expertise in this area

- an appeal process that allows for:

i. oral hearings

ii. the presentation of evidence

iii. the right to call witnesses

iv. the publication of decisions

- the right of asylum seekers to access the judicial system in prescribed circumstances.

\section{On an interim review mechanism:}

The following changes should be made to the operation of the Refugee Status Review Committee as a matter of urgency:

- The position of committee chair should rotate among the members and not be the sole domain of the Department of Immigration.

- The committee should be given decision-making powers (unlike the recommendatory powers they have at present). 
- An additional member of the committee should be appointed whose role is to helpinject a rigorous approach to the decision-making process. There is merit in considering appointing retired judges to this position.

- UNHCR should be given a vote.

\section{On excessive delays in processing asylum claims:}

a) Other than in exceptional circumstances, a primary decision on an asylum claim should be made in no more than six months from the date of application.

b) In the event of a claim being delayed beyond this period, every effort should be made to expedite the process and the applicant should be kept informed of the progress of the claim.

c) While recognizing the need for statutory time limits on procedural requirements, it is necessary to ensure that the procedure employed is fair and does not impinge on the applicant's rights to present all relevant evidence. Therefore, it is necessary that provisions be made for extensions to be granted if good cause can be shown why additional time is required.

\section{On access to the determination process:}

a) No potential applicant for refugee status should be denied the opportunity to present his/her claim to the appropriate authority.

b) If the potential applicant is unable to effectively communicate in English, the services of an accredited interpreter should be employed to enable the person to effectively communicate his/her intentions.

c) Immigration staff at points of entry (or other ports) should be fully briefed on the procedures for dealing with asylum applicants and instructed that if there is any uncertainty about the intention of a person seeking to enter Australia without proper documentation, this person should be regarded as an asylum seeker until established otherwise.

\section{On enforced departure:}

a) Once an asylum seeker has exhausted all legal possibilities to be recognized as a refugee or to obtain permission to stay on any other relevant grounds, assuming the determination procedure is demonstrably fair and just, he/she should leave Australia, either for the home country or another country prepared to accept him/her.

b) There should be counselling for all rejected applicants conducted by appropriately qualified counsellors.

c) Rejected applicants should be offered theopportunity of departing of theirown free will within a specified time frame, with appropriate assistance to be provided before departure and/or after arrival if returning to their home country. d) Only if a rejected applicant declines to leave voluntarily or does not do so within the specified time period, can they be forcibly deported.

e) A rejected applicant should not be forcibly deported to a country that is not a party to the International Covenants and regional treaties relating to human rights.

f) Forced deportation must be undertaken in a manner that protects the safety and dignity of the person(s) concerned and in the presence of an independent observer (such as a UNHCR official or the applicant's adviser).

g) The Australian government should be responsible for liaising with an appropriate international agency (UNHCR or ICRC) to ensure that the applicant will not be subjected to persecution or mistreatment on return to the home country.

\footnotetext{
Refugees and Aylum Seekers in need of Protection and or assistance

Africa ................................ 5,340,800

East Asia/Pacific ..................688,500

Europe/

North America ...................677,700

Latin Americ/

Caribbean .............................119,600

Middle East/

South Asia ...................... 9,820,950

Grand Total ..................... 16,647,550

Source: World refugee Survey-1992
}

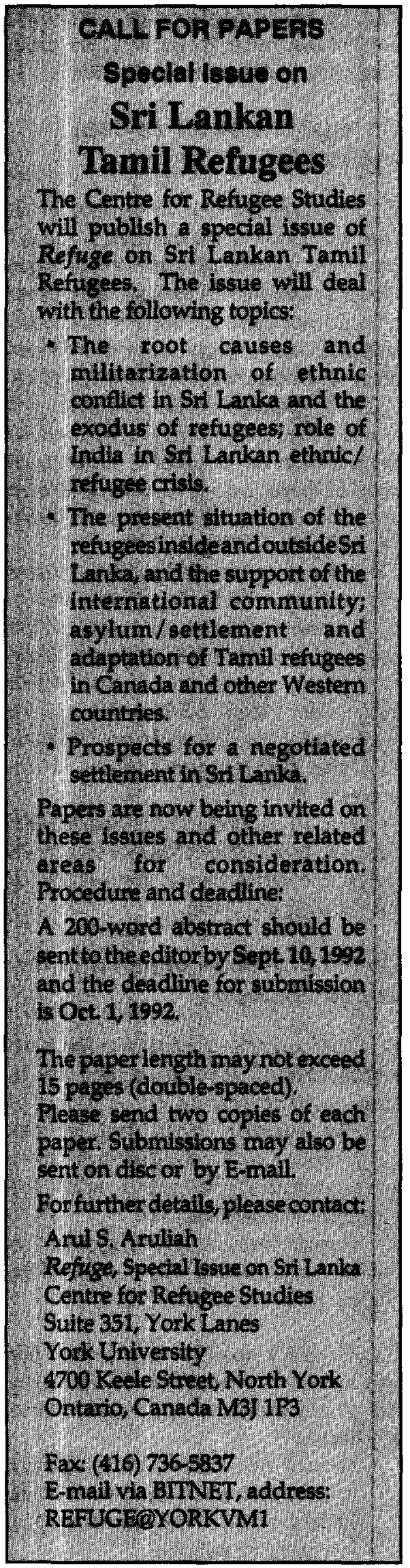

